\title{
Shear Capacity and Failure Behavior of Steel-Reinforced High Ductile Concrete Beams
}

\author{
Mingke Deng, Jie Dai, Huasong Lu, and Xingwen Liang \\ Xian University of Architecture and Technology, Yanta Road 13, Xian 710055, China \\ Correspondence should be addressed to Mingke Deng; dengmingke@126.com
}

Received 10 April 2015; Revised 28 June 2015; Accepted 29 June 2015

Academic Editor: Jainagesh A. Sekhar

Copyright ( 2015 Mingke Deng et al. This is an open access article distributed under the Creative Commons Attribution License, which permits unrestricted use, distribution, and reproduction in any medium, provided the original work is properly cited.

\begin{abstract}
The shear behavior of six high ductile fiber reinforced concrete (HDC) beams is studied to investigate the influence of shearspan ratio and HDC mechanical property on the improvement of the shear failure mode and shear capacity of short beams. Four steel-reinforced high ductile concrete beams (SHDC) beams with different shear span ratios are tested under concentrated load at midspan. To study the effect of stirrups and steel on the shear capacity of short beams, two additional specimens without steel but one including stirrups are investigated. The main aspects of SHDC beams are discussed in detail, such as failure mode, deformability, and shear capacity. Test results show that the SHDC short beams keep high residual bearing capacity and great integrity when suffering from large deformation. It is revealed that HDC increased the shear ductility and improved the shear failure mode of short beams. A comparison with the shear equations of Chinese YB9082-2006 shows that the Chinese Code equation provides conservative estimation for HDC beams. This study proposes modifications to the equation for predicting the shear capacity of HDC beams.
\end{abstract}

\section{Introduction}

With excellent mechanical properties, steel high strength concrete structures have become the best conformation for large span, heavy loading, and superhigh building structures. This structure not only gave full play to the advantages of concrete with high strength and the confinement of steel but also reduced the section dimension of components to enlarge the utility space, leading to enormous social and economic benefits. Due to the brittleness of steel high strength concrete and the relatively poor deformability of short beams, the concrete of SHSC short beams is easily to encounter premature brittle shear failure, producing great restraints on the application of SHSC members in the transfer structures under heavy load. For this reason, it is significant to improve the shear performance of SHSC short beams.

Engineered cementitious composite (ECC) is a kind of high-performance structural material featuring with high strength, superior energy dissipation capacity, high damage tolerance, large deformation capacity, and exceptional durability [1-4]. Studies show that ECC presents high ductility and typical characteristics of multiple fine cracks and tensile strain-hardening behavior under tension or shear loading, which has greatly improved the toughness and crackresistance ability of concrete, especially for the shear performance and damage resistance ability of components [5-7].

In recent years, significant efforts have been placed on using ECC in civil engineering. The flexural behavior of layered ECC-concrete beams has been tested and simulated, indicating that the application of ECC layer leads to an increase in both flexural strength and ductility [8-11]. Tests on a series of composite beams combing a $250 \mathrm{~mm}$ deep reinforced concrete element and a $50 \mathrm{~mm}$ thick reinforced ultra-high-performance fiber reinforced concrete element (R-UHPFRC), subjected to combined bending and shear, revealed that the R-UHPFRC element contributes significantly to the shear resistance [12]. The research by Maalej et al. [13] shows that ECC displays fine shear performance under impact loading. Liang et al. [14] investigated the seismic behavior of small span-depth ratio coupling beams with ECC, and the results indicated that ECC has significantly improved the shear strength, shear ductility, and their damage resistance ability. 
The high ductile fiber reinforced concrete (HDC) used in this paper is a member of ECC family. Based on previous research about $\mathrm{HDC}$ mechanical property $[15,16]$, it is proposed that the failure mode, deformation behavior, and shear capacity of steel-concrete composite beams would be improved by using HDC. The test results of six high ductile fiber reinforced concrete (HDC) beams were studied to investigate the influence of shear-span ratio and HDC mechanical property on the improvement of the shear failure mode and shear capacity of short beams. And a comparison with the shear equations of Chinese YB9082-2006 [17] shows that the Chinese Code equation provides conservative estimation for HDC beams. This study proposes modifications to the equation for predicting the shear capacity of HDC beams more accurately.

The use of high ductile fiber reinforced concrete in steel high strength concrete composite beams can improve its shear behavior and decrease the size of beams in high-rise building, increasing more available floor areas. By testing six HDC short beams, the failure modes, shear capacity, and deformability are investigated in this paper. This research studied the applicability of calculating the shear capacity of steel-concrete composite beams with HDC by the formula in Chinese Code. Based on the test results, two coefficients are proposed for predicting the shear capacity of steel high ductile fiber reinforced concrete by the equation in Chinese Code.

\section{Materials and Methods}

2.1. Materials. In order to meet higher strength and ductility, the test used a HDC mix proportion of cement: flyash : sand : water $=1: 1: 0.72: 0.58$. The maximum size of the sand is $1.18 \mathrm{~mm}$, the cement is P.O.42.5R ordinary Portland cement, the fly-ash is I-level fly-ash from some power plant, and the volume content of PVA fiber is $2 \%$. The mechanical properties of the fiber are shown in Table 1.

2.2. Specimens. Six HDC beams are designed in the test. The HDC strength grade is C60 and the section dimension of each beam is $200 \mathrm{~mm} \times 300 \mathrm{~mm}$. The serial numbers and design parameters of each specimen are shown in Table 2. The strength of reinforcement and HDC is measured in the test. The average value of HDC cubic compressive strength is $69 \mathrm{MPa}$ and its average tensile strength is $5.7 \mathrm{MPa}$ according to uniaxial tensile tests, as shown in Table 3 . The uniaxial tensile curve of HDC in the test is shown in Figure 1. It can be found that the ultimate tensile strain of HDC can reach around $0.8 \%$, showing an evident tensile strain-hardening behavior.

2.3. Methods. Using a 500t electrohydraulic servo testing machine for concentrated load, the test apparatus is shown in Figure 2. In order to avoid local crushing of the specimen, three pieces of steel plates of $140 \mathrm{~mm}$ width were placed under the loading point and the supports. The test was controlled by displacement: the displacement rate was $0.4 \mathrm{~mm} / \mathrm{min}$ before yielding but $1.0 \mathrm{~mm} / \mathrm{min}$ after yielding. The test mainly involves the following aspects: the shear capacity of specimen,
TABle 1: Properties of PVA fiber.

\begin{tabular}{lcccc}
\hline $\begin{array}{l}\text { Fiber } \\
\text { type }\end{array}$ & $\begin{array}{c}\text { Length, } \\
\mathrm{mm}\end{array}$ & $\begin{array}{c}\text { Diameter, } \\
\mathrm{mm}\end{array}$ & $\begin{array}{c}\text { Tensile } \\
\text { strength, } \\
\mathrm{MPa}\end{array}$ & $\begin{array}{c}\text { Tensile } \\
\text { modulus, } \\
\mathrm{GPa}\end{array}$ \\
\hline PVA & 12 & 0.39 & 1600 & 40 \\
\hline
\end{tabular}

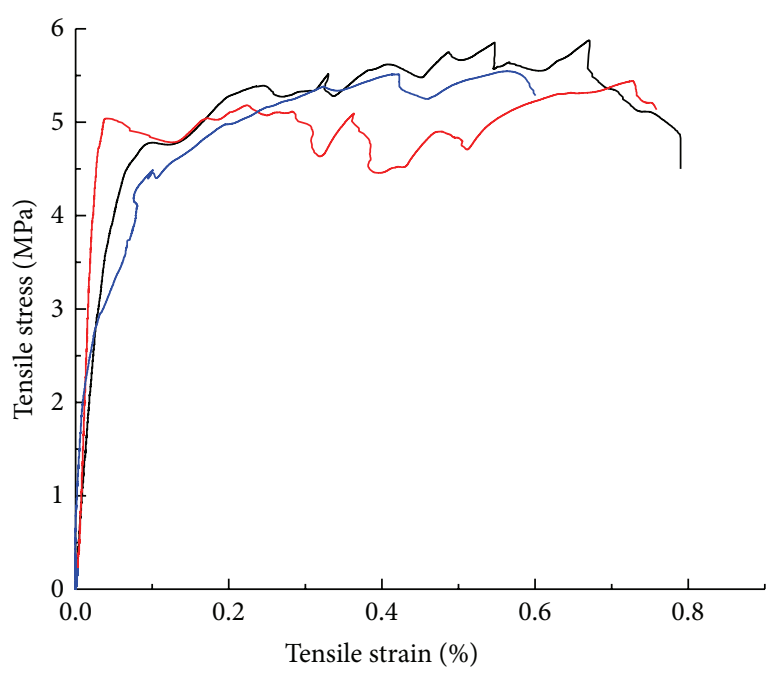

FIGURE 1: Stress-strain curves of uniaxial tensile tests.

midspan deflection, and crack developing, as well as the strain of longitudinal reinforcement, stirrups, steel web, and flange.

\section{Results and Discussion}

All specimens exhibited shear failure, with the longitudinal reinforcement yielded before the final shear failure, as indicated in strain gauge measurements. Additionally, almost all of the web and flange of SHDC Beams were yielded successively in the destruction process. As the excellent tensile strain-hardening behavior and steady propagation of multiple fine cracks of high ductile fiber reinforced concrete, the crack development has been restrained effectively, with the shear behavior of steel-concrete composite beams improved obviously.

3.1. Failure Pattern of HDC Beams. According to the characteristics of loading process, the failure patterns of HDC beams can be divided into extrusion failure, shear-compression failure, shear-bond failure, and flexural-shear failure (Figure 3).

3.1.1. Extrusion Failure (E). Extrusion failure happened to specimen $\mathrm{S}-1(\lambda=1)$ and specimen $\mathrm{S}-15(\lambda=1.5)$.

In HDC specimen $S-1$, a couple of fine flexural cracks formed in the soffit of the beam, and the web-shear cracks constantly increased and extended. The critical diagonal crack broadened after its formation. Afterwards, the steel flange, stirrups, and tensile longitudinal bars yielded successively, and the loading capacity decreased slowly. When the specimen was damaged, an obvious shear dislocation happened between two sides of the critical diagonal crack, as 
TABLE 2: Parameters of specimens.

\begin{tabular}{|c|c|c|c|c|c|}
\hline Beam type & $l_{0}, \mathrm{~mm}$ & Steel & $a / d$ & Stirrup & $\begin{array}{l}\text { Tension/compression } \\
\text { reinforcement }\end{array}$ \\
\hline $\mathrm{D}-2$ & 1500 & \multirow{2}{*}{ - } & 2.0 & - & \multirow{6}{*}{$6 \notin 20 / 2 \$ 16$} \\
\hline $\mathrm{T}-2$ & 1500 & & 2.0 & \multirow{5}{*}{ ф6.5@120 } & \\
\hline S-2 & 1500 & \multirow{4}{*}{$\mathrm{HN} 175 \times 90$} & 2.0 & & \\
\hline S-1 & 900 & & 1.0 & & \\
\hline S-15 & 1200 & & 1.5 & & \\
\hline S-3 & 2100 & & 3 & & \\
\hline
\end{tabular}

TABLE 3: Material properties.

\begin{tabular}{lcccc}
\hline Material & Type & Yield strength, N/mm & Yield strain, $\mu \varepsilon$ & Ultimate strength, N/mm $^{2}$ \\
\hline \multirow{3}{*}{ Reinforcement } & $\phi 6.5$ & 345 & 1643 & 470 \\
& $\$ 16$ & 430 & 2150 & 598 \\
& $\$ 20$ & 418 & 2090 & 590 \\
\hline \multirow{2}{*}{ Steel } & Web & 283 & 1374 & 410 \\
& Flange & 240 & 1165 & 395 \\
\hline
\end{tabular}

well as the local extrusion deformation around the loading point.

The failure process of specimen S-15 is similar to that of specimen S-1. The steel bottom flange yielded first, and the steel web and flange, stirrups and tension reinforcement yielded successively. When the loading increased to $940 \mathrm{kN}$, the diagonal cracks became interconnected to form a critical diagonal crack. Afterwards, many fine diagonal cracks appeared in the shear-compression area, resulting in a slow decrease in the loading capacity of specimen. When the specimen failed, the HDC in the shear-compression area presented large extrusion deformation and a longitudinal splitting crack appeared in the steel bottom flange nearby the right support.

3.1.2. Shear-Compression Failure (SC). Shear-compression failure happened to specimens D-2 (without stirrups) and T-2 (with stirrups).

The tensile longitudinal bars of specimen D-2 started to yield at $240 \mathrm{kN}$, and the flexural and web-shear cracks both increased and extended. Later, the critical diagonal crack in the web gradually broadened after its appearance. With the slowly increased loading, several fine diagonal cracks appeared in the loading point. Finally the specimen failed when the HDC of shear-compression zone reached its strength under combined loads.

In the loading process of T-2, stirrups, tension reinforcement, and compression reinforcement yielded in succession, producing many fine diagonal cracks in the web of beam. When reaching the peak load, the diagonal cracks became interconnected to form a critical diagonal crack with the declining of loading capacity. When the failure occurred, the HDC on both sides of critical diagonal cracks put on obvious shear dislocation.

3.1.3. Shear-Bonding Failure (SB). Shear-bonding failure happened to specimen S-2 (with stirrups and steel). The steel flange, stirrups, steel web, and tension reinforcement yielded successively, and subsequently a main diagonal crack formed at the web of beam. When reaching the peak load, a longitudinal slipping crack formed and broadened at the lower steel flange, producing a significant decrease in loading capacity. After that, the shear slipping crack slowly extended to the support while the loading gradually increased.

3.1.4. Flexural-Shear Failure (FS). Flexural-shear failure happened to specimen $S-3(\lambda=3)$. In the loading process, the steel flange, tension longitudinal reinforcement, and compression reinforcement yielded one by one. Then, a flexural crack diagonally developed to form a flexural-shear crack. When tensile yielding happened to stirrups and steel web, a main diagonal crack formed at the beam abdomen, and the HDC at the compression zone was slightly protruded. Finally, the specimen deformed constantly, with flexural and diagonal cracks increasing constantly, but there was no evident decrease in the loading capacity of specimen.

3.2. Shear Failure Mechanism. According to the comparison and analysis of the failure modes involving the above six HDC beams, the following conclusions could be obtained:

(1) For SHDC short beams with very small shear-span ratio (specimens S-1 and S-15), when loading to 60 percent of its ultimate loading, several parallel diagonal cracks (main diagonal cracks) with long extension and wide development showed up at the beam abdomen. As loading increases, a diagonal compression struts formed between HDC diagonal cracks. However, "the diagonal compression struts" did not crush but produced an evident shear dislocation and extrusion flow due to the good tensile strain-hardening behavior and plastic deforming capacity of HDC, which is called extrusion failure. This failure mode has obvious distinction with diagonal-compression failure of concrete short beams for the former is featured with high loading capacity, good ductility, and perfect completeness after the specimen failure. 


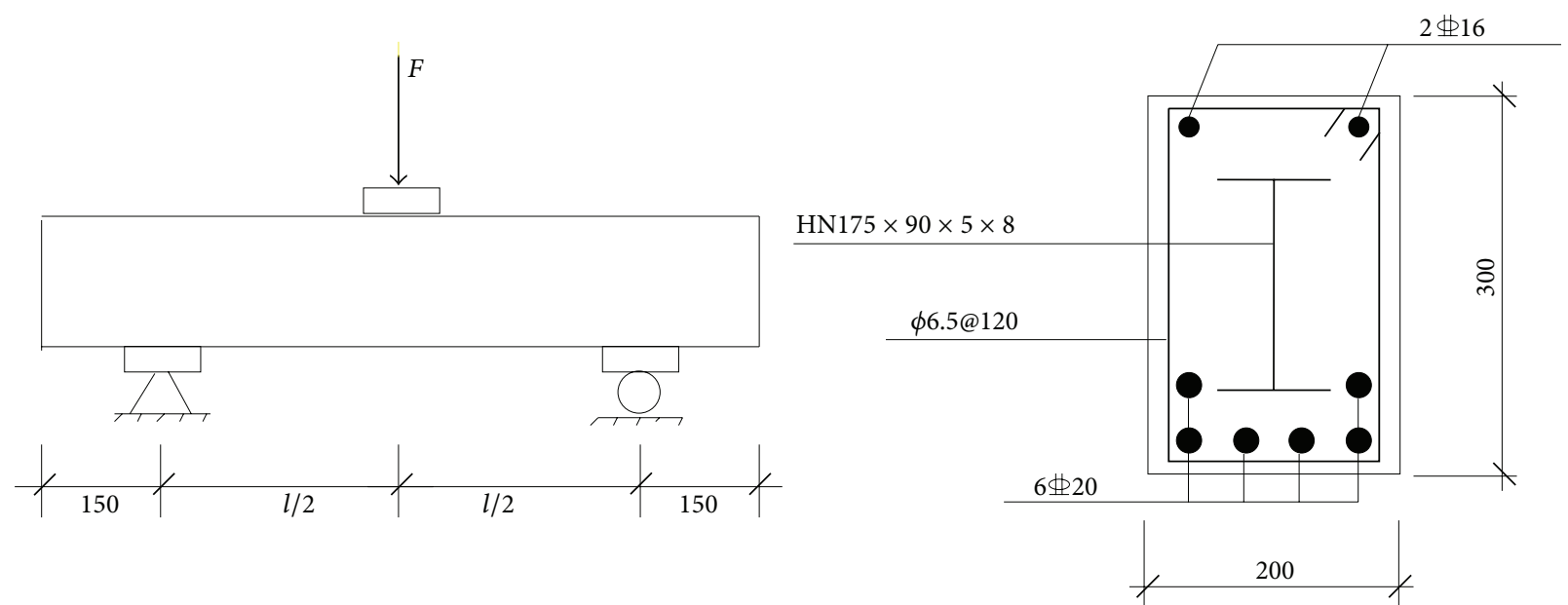

FIgURE 2: Test apparatus and specimen details.

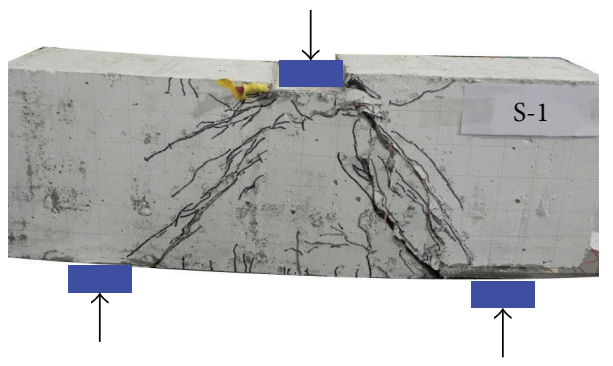

(a) S-1

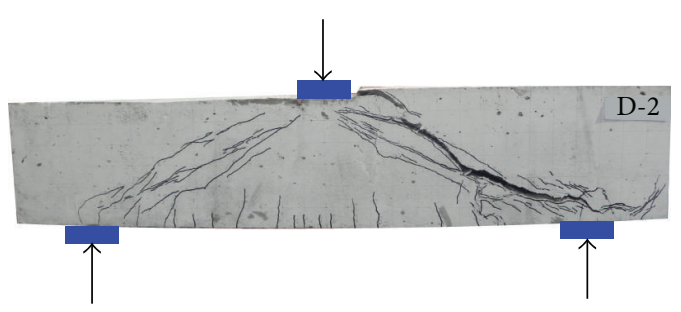

(c) $\mathrm{D}-2$

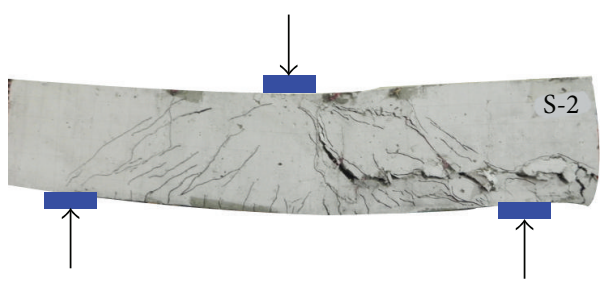

(e) S-2

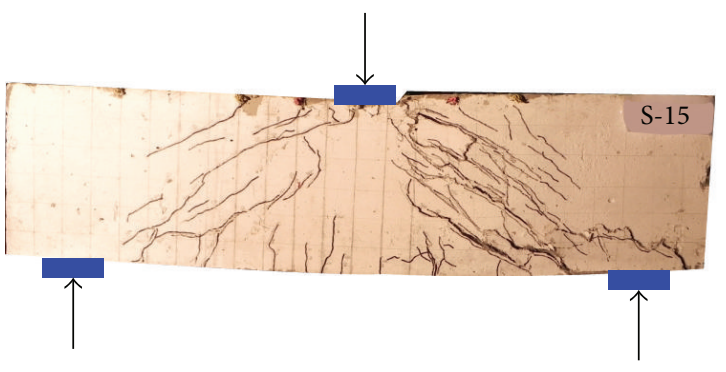

(b) S-15

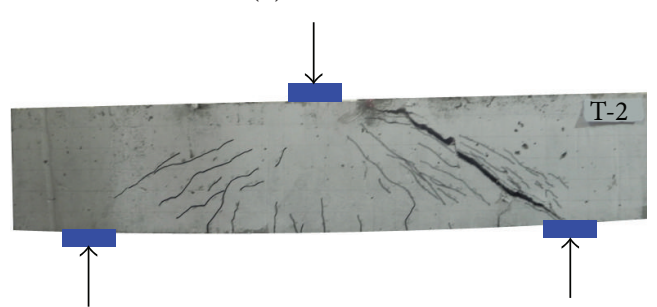

(d) $\mathrm{T}-2$

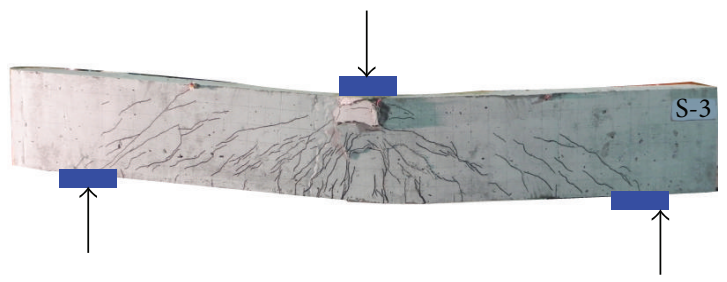

(f) S-3

FIGURE 3: The failure pattern of specimens.

(2) For the short beams of small shear-span ratio without stirrups (D-2), when loading to 75 percent of the ultimate loading, a main diagonal crack (or critical diagonal crack) with long extension and wide development appeared at the beam abdomen. As loading increases, the critical diagonal crack gradually extended towards the loading point, reducing the height of shear-compression zone and producing a shear-compression failure when the HDC reached its combined strength under shear and compression loading.

(3) For the short beams of small shear-span ratio with stirrups (T-2), those stirrups can exert a constraint impact on specimen after the appearance of web-shear cracks, and most stirrups yielded before the peak load. As the loading capacity deceases, the critical diagonal crack gradually widened and 

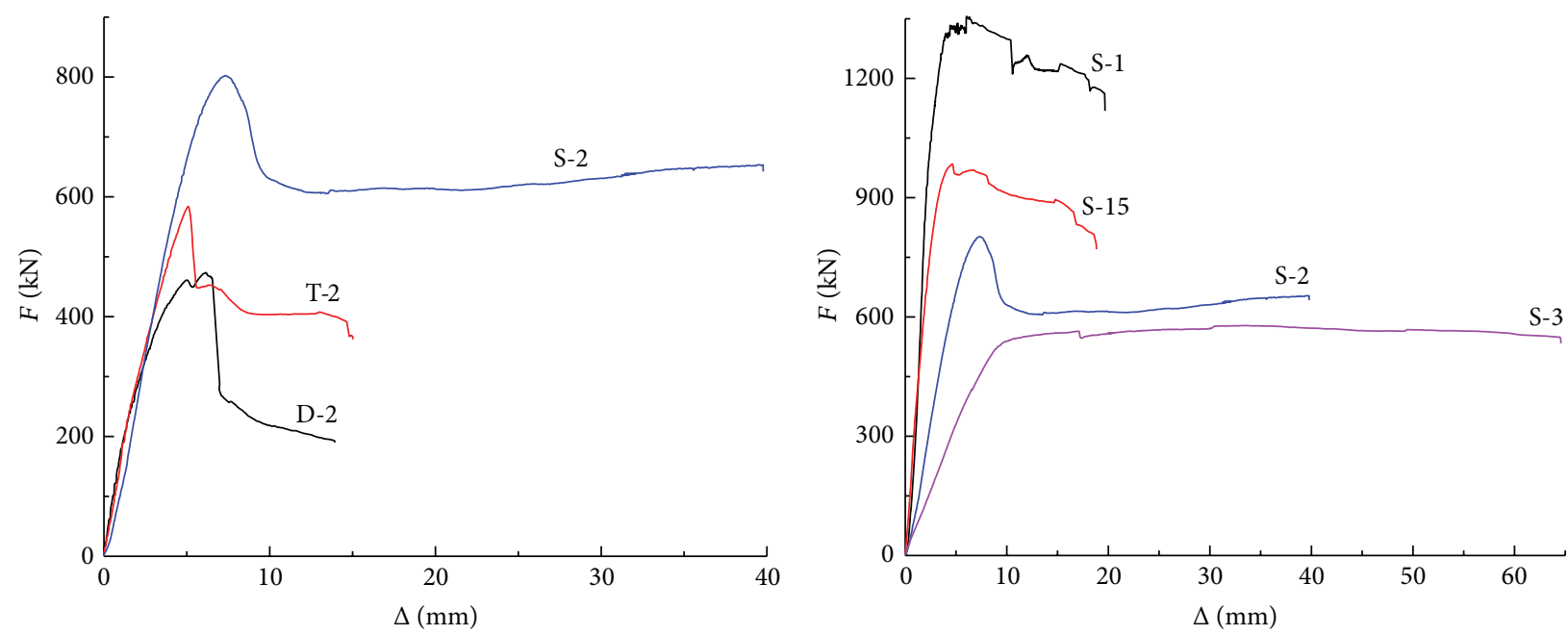

Figure 4: Load-deflection curves of all specimens.

shear-compression failure with some degree of ductility occurred ultimately. When the failure happened to T-2, an evident dislocation appeared between the two sides of critical diagonal crack, HDC did not peel off, and the specimen always remained integrated.

(4) For short beams of SHDC with relatively small shearspan ratio (S-2), the great confinement of stirrups and steel on the HDC in shear-compression zone has enormously increased the loading capacity and ductility of specimens. However, the shortage of bonding strength between steel and HDC led to shear-bonding failure of both specimens when reaching their peak load. When the shear-bonding failure happened to specimen S-2, HDC only peeled off a little and did not damage too much. In the process of failure, the loading capacity of specimen evidently rebounded, presenting a fact that the SHDC beams kept relatively nice ductility and residual loading capacity even after the failure.

(5) For SHDC beam with large shear-span ratio (specimen S-3), evident multiple cracking occurred in the midspan and web of beam, owing to the excellent tensile strainhardening behavior and fiber bridging effect of HDC. Flexural cracks and web-shear cracks extended rapidly after the yielding of tension reinforcement, with the height of shearcompression zone kept reducing. Finally, the failure occurred when HDC reached its combined strength under shear and compression.

Specimen S-3 kept high loading capacity even after the occurrence of slight protruding when flexural-shear failure with nice ductility happened. The specimen kept good integrity after dramatic deformation with a low degree of damage, which will be beneficial for the reinforcement and restoration of structures after earthquake.

3.3. Load-Deflection Curve. Load-deflection curves of six specimens were shown in Figure 4 . The appearance of an evident crack on specimen was used to determine its crack loading and corresponding displacement; a corresponding load and displacement at the maximum loading point were used to determine the peak load and displacement; when the loading capacity dropped to 85 percent of its peak load, the corresponding point at the curve was used to determine the ultimate displacement; and the ratio of ultimate displacement to yield displacement was used to determine the displacement ductility factor, where the yield displacement was determined by "general moment yield method." The comparison of feature points and displacement ductility factors can be seen in Table 4. The analysis and comparison from Figure 4 and Table 4 show the following:

(1) Shear-compression failure happened to specimens D2 and T-2 with a certain degree of ductility, with gentle loaddeflection curves. All the stirrups yielded before the forming of the main diagonal crack on specimen T-2, and the shear capacity dropped greatly at the peak of loading. But the load-deflection curve became steady after that. The reason is that the stirrups in HDC beams were not enough to meet the requirement of minimum stirrup ratio calculated by the tested tensile strength of HDC.

(2) Shear-bonding failure happened to specimen S-2, the loading-deflection curve dropped greatly after reaching the peak loading, and the ductility factor was low. The integrity of specimen S-2 was preserved well all the time because of the great tensile strain-hardening behavior and fiber bridging effect of HDC, especially after the appearance of shear slippage crack. Finally, the curve rebounded and showed nice ductility.

(3) Extrusion failure happened to specimens S-1 and $\mathrm{S}-15$; the loading-deflection curve of them was kept as a straight line before reaching 65 percent of their peak load and decreased gently after the peak load with, which showed high ductility.

(4) Flexural-shear failure happened to specimen S-3; the loading-deflection curve of them was kept as a straight line before reaching 75 percent of its peak load and had no evident decrease with increasing deformation of specimen, which showed great ductility. 
TABLE 4: Comparisons of characteristic point and displacement.

\begin{tabular}{|c|c|c|c|c|c|c|c|c|c|c|c|c|}
\hline \multirow[b]{2}{*}{ Beam } & \multirow[b]{2}{*}{$\lambda$} & \multicolumn{3}{|c|}{ Diagonal cracking } & \multicolumn{3}{|c|}{ Critical diagonal cracking } & \multicolumn{3}{|c|}{ Ultimate shear capacity } & \multirow[b]{2}{*}{ Ductility } & \multirow[b]{2}{*}{ Failure mode } \\
\hline & & $\begin{array}{l}F_{\mathrm{cr}} \\
\mathrm{kN}\end{array}$ & $\begin{array}{l}\Delta_{\mathrm{cr}} \\
\mathrm{mm}\end{array}$ & $\Delta_{\mathrm{cr}} / l$ & $\begin{array}{l}F_{k} \\
\mathrm{kN}\end{array}$ & $\begin{array}{l}\Delta_{k} \\
\mathrm{~mm}\end{array}$ & $\Delta_{k} / l$ & $\begin{array}{l}F_{m} \\
\mathrm{kN}\end{array}$ & $\begin{array}{l}\Delta_{m} \\
\mathrm{~mm}\end{array}$ & $\Delta_{m} / l$ & & \\
\hline $\mathrm{D}-2$ & 2.1 & 200 & 1.2 & $1 / 1000$ & 340 & 2.7 & $1 / 444$ & 473 & 6.1 & $1 / 197$ & 1.84 & SC \\
\hline $\mathrm{T}-2$ & 2.1 & 150 & 0.7 & $1 / 1714$ & 550 & 4.5 & $1 / 267$ & 584 & 4.8 & $1 / 250$ & 1.22 & SC \\
\hline S-2 & 2.1 & 310 & 2.3 & $1 / 522$ & 745 & 5.9 & $1 / 203$ & 802 & 7.4 & $1 / 162$ & 1.44 & SB \\
\hline S-1 & 1.1 & 350 & 1.1 & $1 / 545$ & 1260 & 3.5 & $1 / 171$ & 1356 & 6.1 & $1 / 98$ & 6.08 & $\mathrm{E}$ \\
\hline S-15 & 1.6 & 540 & 1.6 & $1 / 563$ & 940 & 3.6 & $1 / 250$ & 985 & 4.7 & $1 / 191$ & 4.97 & $\mathrm{E}$ \\
\hline S-3 & 3.1 & 230 & 3.5 & $1 / 514$ & 570 & 29.3 & $1 / 61$ & 578 & 33.3 & $1 / 54$ & $>6.6$ & FS \\
\hline
\end{tabular}

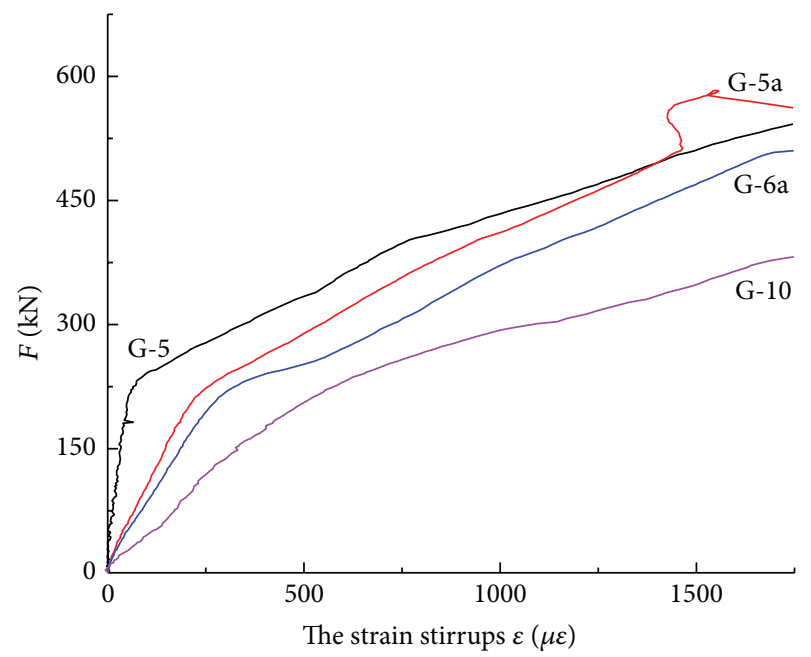

(a) T-2

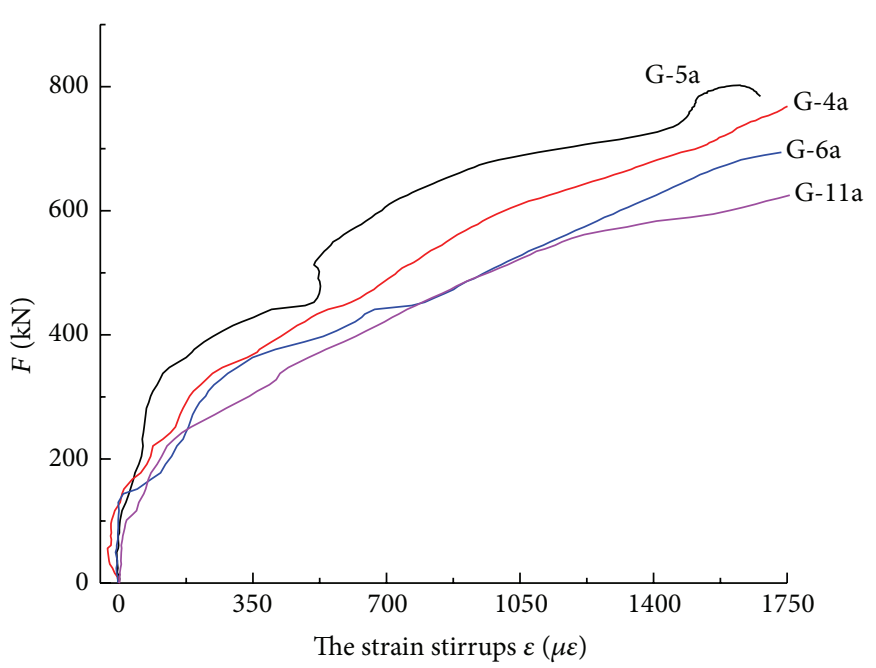

(b) S-2

FIGURE 5: The strain of beam stirrups.

(5) The common feature of specimens S-1, S-15, and S-2 is as follows: the above specimens kept their loading capacity above 80 percent with significant deformation, presenting that SHDC beams have high residual loading capacity and HDC can greatly improve the shear ductility of short beams.

Due to the great tensile strain-hardening behavior and fiber bridging effect of HDC, the HDC in shear-tension zone kept its loading capacity after cracking, which effectively inhibited the development of crack in flexural-shear zone, while enhancing the beam's deformation capacity before the appearance of critical crack. Besides, as the ultimate compression strain of HDC was much higher than that of the concrete, the HDC in shear-compression zone had strong extrusion deformation after the forming of critical crack when the shear-compression and flexural-shear failure happened to HDC beams, leading to an evident yield plateau at loaddeflection curves and enormous increase in the deformation ability of specimens.

3.4. Stirrup Strain Analysis. According to the load-stirrup strain curves of the two specimens shown in Figure 5, the following can be found:

(1) The stirrup strain was very weak before the appearance of diagonal cracks at the beam abdomen but the diagonal cracks grew dramatically after its appearance.
(2) For specimen T-2, almost all the stirrups yielded before the formation of critical diagonal cracks, and the critical diagonal cracks widened rapidly at the peak load.

(3) The high shear deformation capacity of HDC enabled most stirrups to yield even before the peak load of specimen T-2, which demonstrated that stirrups of it were not enough to give specimen a full play of its shear capacity.

(4) Shear-bonding failure happened to specimen S-2 and most stirrups were not yielded at peak load.

(5) Flexural-shear failure happened to specimen S-3; the stirrups and steel web were not yielded at peak load. Therefore, the shear capacity of S-3 has not been fully utilized.

3.5. Prediction of Ultimate Shear Strength. According to technical specification of steel-reinforced concrete composites structures (YB9082-2006), the shear strength of six specimens was calculated and then compared with the test results, as shown in Table 5. There is a significant difference between the calculation and test results. Since the tensile strength and the ultimate tensile strain of the HDC are greater than those of RC, it is proposed in the paper that HDC tensile strength increase of coefficient $\eta$ and ductility increase of coefficient $\delta$ should be taken into consideration so as to revise the shear capacity formula. The latter coefficient, $\delta$, mainly reflects 
TABLE 5: Comparison between calculation and test values.

\begin{tabular}{lccccccc}
\hline Beam & $V_{\text {exp }}, \mathrm{kN}$ & $V_{\text {YB }}, \mathrm{kN}$ & $V_{\text {exp }} / V_{\text {YB }}$ & $k$ & $\delta$ & $V_{C}, \mathrm{kN}$ \\
\hline D-2 & 236.50 & 126.40 & 1.87 & 1.92 & 1.31 & 238.90 \\
T-2 & 292.00 & 179.53 & 1.63 & 1.94 & 1.33 & 292.03 \\
S-2 & 401.00 & 303.61 & 1.32 & 1.93 & 1.32 & 401.66 \\
S-1 & 678.00 & 342.38 & 1.98 & 2.95 & 2.02 & 663.24 \\
S-15 & 492.50 & 328.96 & 1.50 & 2.29 & 1.57 & 495.19 \\
S-3 & 289.00 & 282.85 & 1.02 & 1.29 & 0.88 & 300.68 \\
\hline
\end{tabular}

* Due to the fact that the flexural-shear failure happened to specimen S-3, the experimental value was less than the calculated one by YB9082-2006.

the increase effect of tensile strain-hardening behavior and ultimate tensile strain to the shear capacity of HDC beam.

On the basis of YB9082-2006, the shear capacity of steelreinforced concrete under concentrated loading is composed of steel and reinforced concrete. The formula is

$$
V_{b}=\frac{1.75}{\lambda+1} f_{t} b_{b} h_{b 0}+f_{y v} \frac{A_{s v}}{s} h_{b 0}+t_{w} h_{w} f_{s s v}
$$

where $\lambda$ represents the shear-span ratio; $t_{w}$ is the thickness of steel webs; $h_{w}$ is the height of steel webs; $f_{s s v}$ is the design shear strength of steel webs.

3.5.1. Increase Coefficient of Tensile Strength $\eta$. The tensile strength of concrete is 4.05 when the compressive strength of concrete is equal to HDC in this paper, which is calculated by $f_{t}=0.395 f_{\mathrm{cu}}^{0.55}$. According to the test results, the tensile strength of HDC is much higher than that of common concrete of the same strength. Thus, the increase coefficient $\eta$ should be taken into consideration of HDC tensile strength to the shear capacity of short beams:

$$
\eta=\frac{f_{t}^{d} / f_{c}^{d}}{f_{t}^{c} / f_{c}^{c}}=1.41
$$

3.5.2. Increase Coefficient of Ductility $\delta$. The experimental results show that the ductility increase coefficient $\delta$ has been decreased with the increase of shear-span ratio. Regression analysis is made according to the test results and the relationship between $\delta$ and $\lambda$, as shown in Figure 6 .

To set the shear increase coefficient $k=\eta \delta$, a revised formula can be deduced for the shear capacity of steel HDC beams in accordance with technical specification of steelreinforced concrete composites structures:

$$
V_{b}=\frac{1.75}{\lambda+1} k f_{t} b_{b} h_{b 0}+f_{y v} \frac{A_{s v}}{s} h_{b 0}+t_{w} h_{w} f_{s s v} .
$$

The mean strength value of HDC can be measured in the test, and the mean strength value of concrete can be calculated, so the shear capacity of the beams can be calculated, as shown in Table 5. As flexural-shear failure happens to specimen S-3, the shear increase coefficient $k$ calculated from experiment is a little smaller.

\section{Conclusion}

Through the tests results on the shear capacity of the six HDC beams, the following can be concluded:

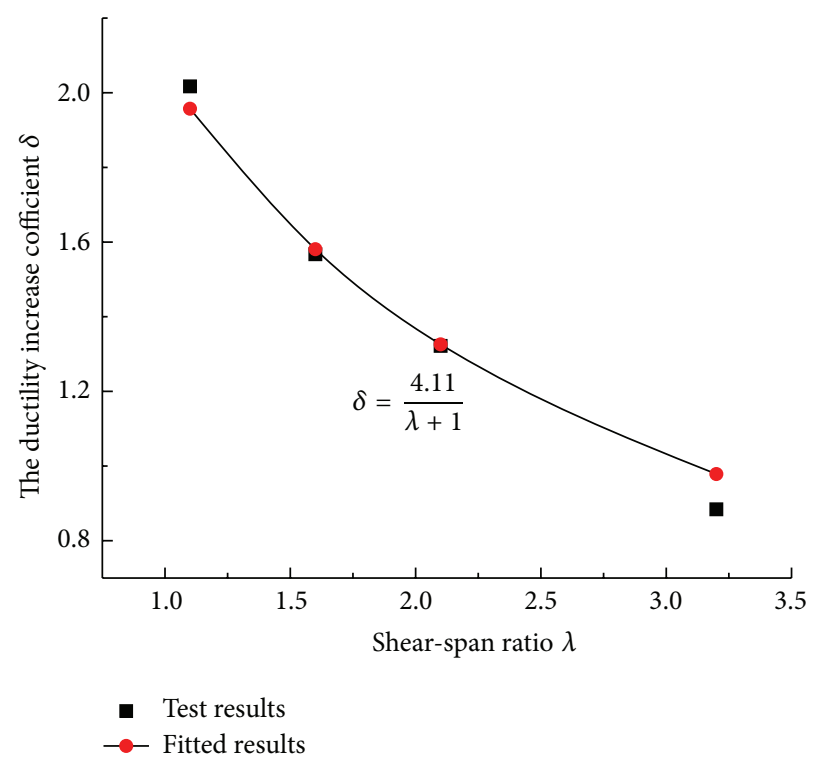

FIgURE 6: $\delta$ - $\lambda$ according to YB9082-2006.

(1) The outstanding tensile strain-hardening effect and good damage tolerance capability could improve the shear capacity of short beams, achieving ductile shear failure mode.

(2) The powerful deformation capacity of HDC (much better than concrete) in the shear-compression zone produced a significant growth for the loading capacity and deformation capacity of SHDC short beams. All HDC specimens displays good ability to resist damage, which will be beneficial to the reinforcement and restoration after earthquake.

(3) The SHDC short beams with small shear-span ratio occurring extrusive failure have higher carrying capacity and have good integrity after being broken. And SHDC beams only had a little injury after shear-bonding failure, featuring high residual loading capacity and good ductility after the destruction.

(4) The analysis on the strain of stirrups shows that the good shear deformation ability of HDC enabled most stirrups to yield before reaching the peak load of specimen. The stirrups are not enough to give the shear ability of SHDC specimen a full play. Thus, the stirrups reinforcement ratio should be raised for SHDC beams.

(5) The increase coefficient $k$ of HDC to the shear capacity of short beam is related to HDC tensile strength increase 
coefficient $\eta$ and ductility increase coefficient $\delta . \delta$ declines with the rise of shear-span ratio of HDC beam; that is, HDC material ductility has a significant improvement effect on the shear capacity of short beam, which should be taken into consideration in the design.

(6) According to YB9082-2006, the formula to calculate the shear strength of SHDC beams has been proposed, which has taken into account the tensile strength increase coefficient $\eta$ and the ductility increase coefficient $\delta$. And the calculated values have a good agreement with experimental results.

\section{Conflict of Interests}

The authors declare that there is no conflict of interests regarding the publication of this paper.

\section{Acknowledgments}

The experimental work was carried out in the Structure Laboratory of the School of Civil Engineering, Xian University of Architecture and Technology, Shaanxi Province, China. The present work was financially supported by the Project of Science and Technology plan of Xi'an, China (no. CX131353).

\section{References}

[1] V. C. Li and C. K. Y. Leung, "Steady-state and multiple cracking of short random fiber composites," Journal of Engineering Mechanics, vol. 118, no. 11, pp. 2246-2264, 1992.

[2] V. C. Li, "ECC-tailored composites through micromechanical modeling," in Fiber Reinforced Concrete: Present and the Future, N. Banthia, A. Bentur, and A. Mufti, Eds., pp. 64-97, CSCE, Montreal, Canada, 1998.

[3] V.C. Li, S. Wang, and C. Wu, "Tensile strain-hardening behavior of PVA-ECC," ACI Materials Journal, vol. 98, no. 6, pp. 483-492, 2001.

[4] V. C. Li, "On engineered cementitious composites (ECC) - a review of the material and its applications," Journal of Advanced Concrete Technology, vol. 1, no. 3, pp. 215-230, 2003.

[5] P. Kabele and T. Kanakubo, "Experimental and numerical investigation of shear behavior of PVA-ECC in structural elements," in Proceeding, Fifth International RILEM Workshop on High Performance Fiber Reinforced Cement Composites (HPFRCC5), H. W. Reinhardt and A. E. Naaman, Eds., pp. 137-146, RILEM, 2007.

[6] G. Fischer and V. C. Li, "Influence of matrix ductility on tensionstiffening behavior of steel reinforced Engineered Cementitious Composites (ECC)," ACI Structural Journal, vol. 99, no. 1, pp. 104-111, 2002.

[7] G. Fischer and V. C. Li, "Effect of matrix ductility on deformation behavior of steel reinforced ECC flexural members under reversed cyclic loading conditions," ACI Structural Journal, vol. 99, no. 6, pp. 781-790, 2002.

[8] J. Zhang, C. K. Y. Leung, and Y. N. Cheung, "Flexural performance of layered ECC-concrete composite beam," Composites Science and Technology, vol. 66, no. 11-12, pp. 1501-1512, 2006.

[9] C. K. Y. Leung, Y. N. Cheung, and J. Zhang, "Fatigue enhancement of concrete beam with ECC layer," Cement and Concrete Research, vol. 37, no. 5, pp. 743-750, 2007.
[10] S. K. Shin, J. J. H. Kim, and Y. M. Lim, "Investigation of the strengthening effect of DFRCC applied to plain concrete beams," Cement and Concrete Composites, vol. 29, no. 6, pp. 465473, 2007.

[11] M. Maalej and V. C. Li, "Introduction of strain-hardening engineered cementitious composites in design of reinforced concrete flexural members for improved durability," ACI Structural Journal, vol. 92, no. 2, 1995.

[12] T. Noshiravani and E. Bruhwiler, "Experimental investigation on reinforced ultra-high-performance fiber-reinforced concrete composite beams subjected to combined bending and shear," ACI Structural Journal, vol. 110, no. 2, pp. 251-262, 2013.

[13] M. Maalej, J. Zhang, S. T. Quek et al., "High-velocity impact resistance of hybrid-fiber engineered cementitious composites," in Proceedings of the 5th International Conference on Fracture Mechanics of Concrete and Concrete Structures (FRAMCOS '04), pp. 1051-1058, International Association of FraMCoS, Vail, Colo, USA, 2004.

[14] X. W. Liang, J. L. Che, and M. K. Deng, "Experimental research on seismic behavior of diagonally reinforced FRC coupling beams with small span-to-depth ratio," Journal of Building Structures, vol. 34, no. 8, pp. 135-141, 2013 (Chinese).

[15] Y. Li, X. W. Liang, and M. K. Deng, "Reinforced cement composites under conventional tri-axial compression," Engineering Mechanics, vol. 29, no. 1, pp. 106-113, 2012 (Chinese).

[16] M. K. Deng, H. Z. Sun, X. W. Liang et al., "Experimental study on flexural behavior of high ductile fiber reinforced concrete," Industrial Construction, vol. 20, no. 5, pp. 85-90, 2014 (Chinese).

[17] YB, “Technical specification of steel-reinforced concrete structures,” YB 9082-2006, Metallurgical Industry Press, 2006. 

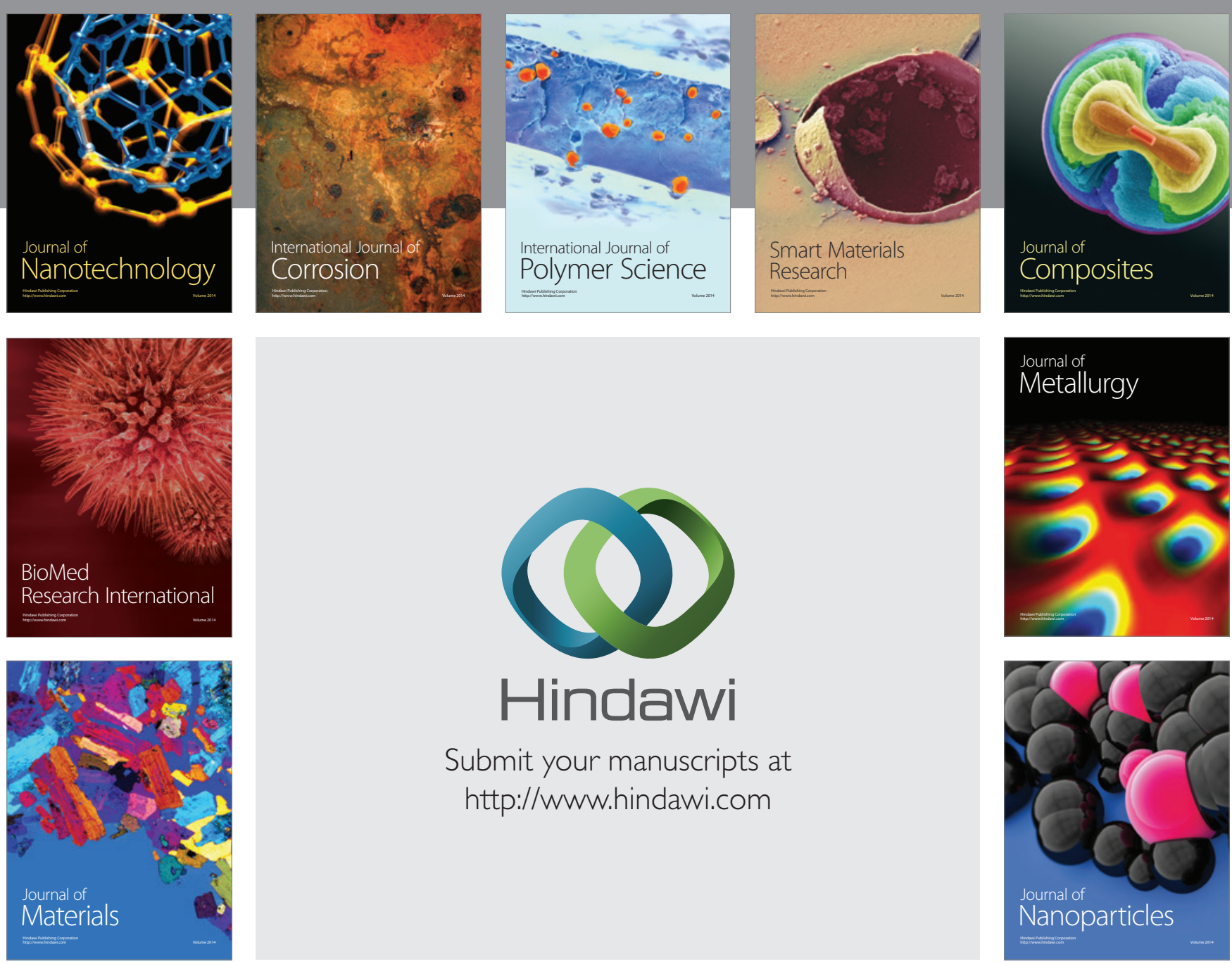

Submit your manuscripts at http://www.hindawi.com
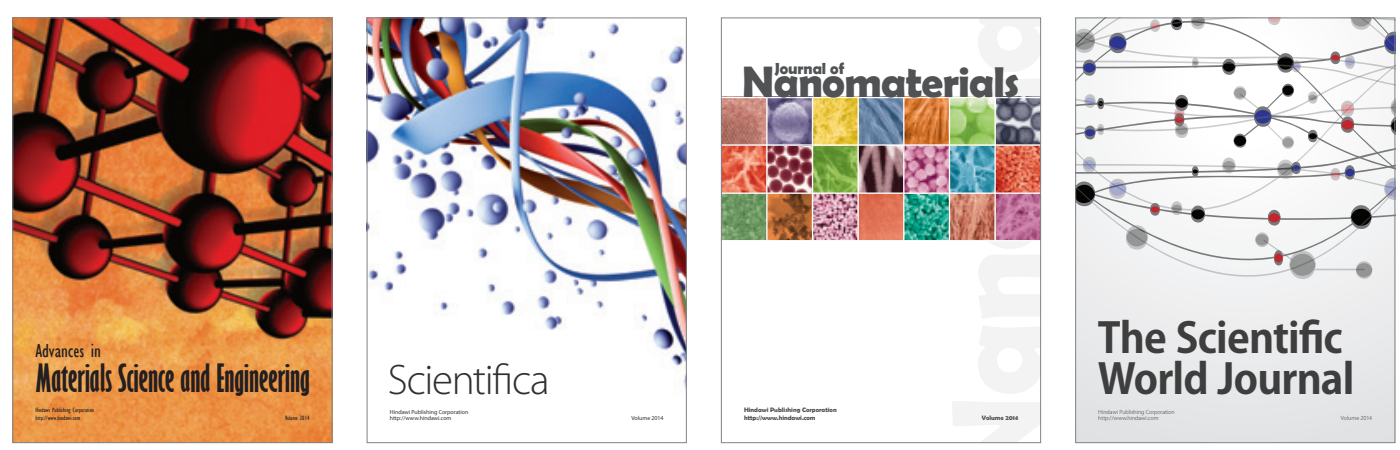

\section{The Scientific World Journal}
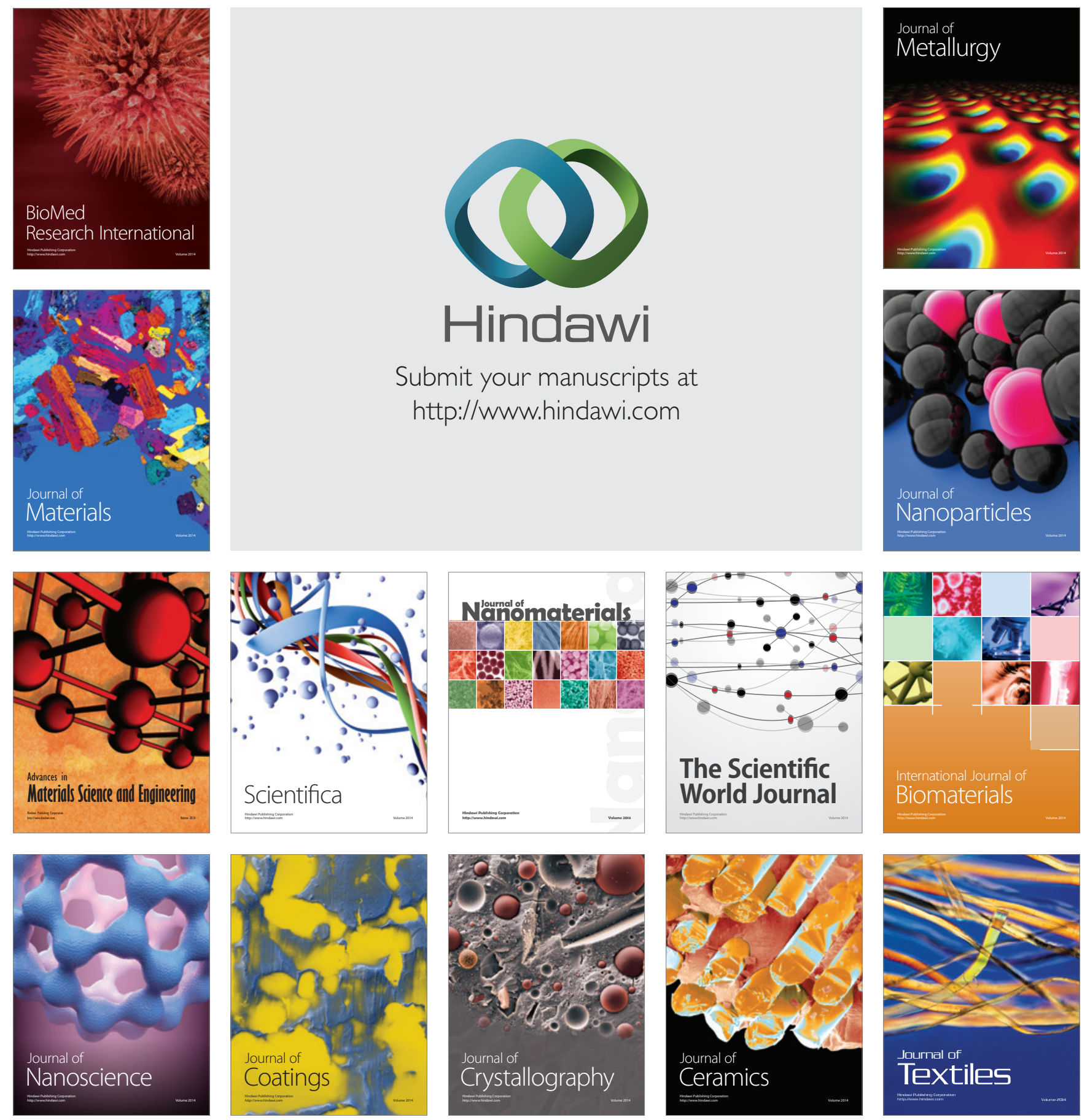